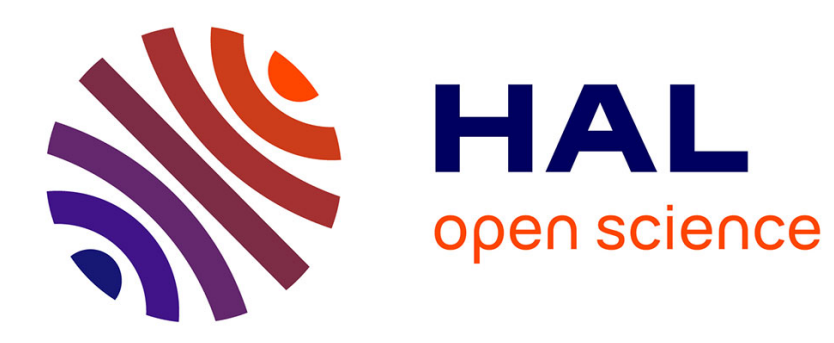

\title{
REFLECTION SAXS INVESTIGATION OF AMORPHOUS THIN FILMS
}

\author{
R. Manaila
}

\section{To cite this version:}

R. Manaila. REFLECTION SAXS INVESTIGATION OF AMORPHOUS THIN FILMS. Journal de

Physique Colloques, 1981, 42 (C4), pp.C4-213-C4-216. 10.1051/jphyscol:1981444 . jpa-00220901

\section{HAL Id: jpa-00220901 https://hal.science/jpa-00220901}

Submitted on 1 Jan 1981

HAL is a multi-disciplinary open access archive for the deposit and dissemination of scientific research documents, whether they are published or not. The documents may come from teaching and research institutions in France or abroad, or from public or private research centers.
L'archive ouverte pluridisciplinaire HAL, est destinée au dépôt et à la diffusion de documents scientifiques de niveau recherche, publiés ou non, émanant des établissements d'enseignement et de recherche français ou étrangers, des laboratoires publics ou privés. 
R. Manaila

Institute of Physics and Technology of Materials, Bucharest, P.0. Box MG-7, Romania

\begin{abstract}
The present work points out the advantages of a reflection variant of small-angle $x$-ray scattering(RSAXS) in the study of amorphous thin films.The method is applied to amorphous $\mathrm{Mo}_{\mathrm{X}}(\mathrm{a}-\mathrm{Ge}) I_{-\mathrm{x}}$ films $(0.07 \leqslant \mathrm{x} \leqslant 0.32)$, allowing the determination of the size distribution and magnitude of the compositional fluctuations.
\end{abstract}

Introduction.- The present increasing interest in the microstructure of the amorphous films [1] requires adequate structural methods to assess quantitatively the existing fluctuations in density and/or composition. On the other hand, thin films are usually difficult to be removed from the substrate, in order to be submitted to conventional transmission small-angle $\mathrm{X}$-ray investigations.

A reflection SAXS method(RSAXS) is particularly suitable in the study of films $10^{3}-10^{4} \&$ thick, as the glancing incidence amplifies the beam pati in the material by a factor 1/sine. Also, the diffracted intensity is better averaged, due to the large irradiated area. For thinner films or low absorption coefficients an absorption correction may be required.

As very little is known nowadays about the structure of amorphous surfaces and underlying layers, RSAXS could also open new investigation possibilities in this field.Surface mechanical imperfections and oxide layers can also give rise to scattering effects [2], but they are usually concentrated in the range of very small $k=4 \pi s i n \theta / \lambda$.

When used with a parafocusing geometry, RSAXS is sensitive only to the fluctuation component which is normal to the film surface. Therefore, it is expected to give useful information in the case of anisotropic voids, reported in evaporated and sputtered a-Ge films [3] .

Experimental technique.- RSAXS relies on the strong limitation of the equatorial divergence in a Bragg-Brentano diffractometric set-up.Our experiments were performed with a small-angle device mounted on the sample holder of a conventional siemens diffractometer. The equatorial divergence was limited by means of a Au-plated edge,parallel to the sample surface at a variable distance. The divergence of the beam was about 2.10-3 rad, which corresponds to a resolution $\Delta k$ of $2.10^{-2} \AA^{-1}$ for the Cuk wavelength which was used.Th1s is to be compared with a typical equatorial divergence of $1.10^{-4}$ rad in conventional sAxs cameras.

Thus, reflection SAXS can be useful mainly in problems which do not require a high resolution.Also, in our experiments the measurable $\mathrm{k}$ range extended downwards to about $6 \cdot 10^{-2} \AA^{-1}\left(2 \theta=0.8^{\circ}\right)$, due to the limited length of the sample.This limitation is also related to the proximity of the total reflection incidence angle.

RSAXS effects are superposed onto the sample volume scattering. In a Fresnel formalism applied to the diffractometer geometry, a sam- 
ple of uniform electron density $\rho$ will scatter a small-angle intensity $I_{0}(k) \sim k^{-4}[4]$, although this dependence can be easily distorted by an imperfect planeity of the sample surface. Any density fluctuations in the size range 10-102 \& will modulate this average scattering and this effect can be treated in the Fraunhofer approximation, due to the investigated distances being small in comparison with the sample length.

Inhomogeneities in cermet-type Mo (a-Ge) $1-x$ thin films.- The present work report RSAXS results obtained on amorphous cermet $\mathrm{Mo}_{\mathrm{x}}(\mathrm{a}-\mathrm{Ge})$ 1-x thin films with $x=0.07,0.22$ and 0.32 .

The films were obtained by co-evaporation onto fused silica substrates and had thickness in the range $(2-3) .10^{3} \AA$. Detailed results on their structure and electrical properties were reported in [5]. The scattered intensity obtained by RSAXS on these films is shown in fig.1. The cermet films display strong intensity modulations, superposed on to a smoothly warying volume scattering. The modulations

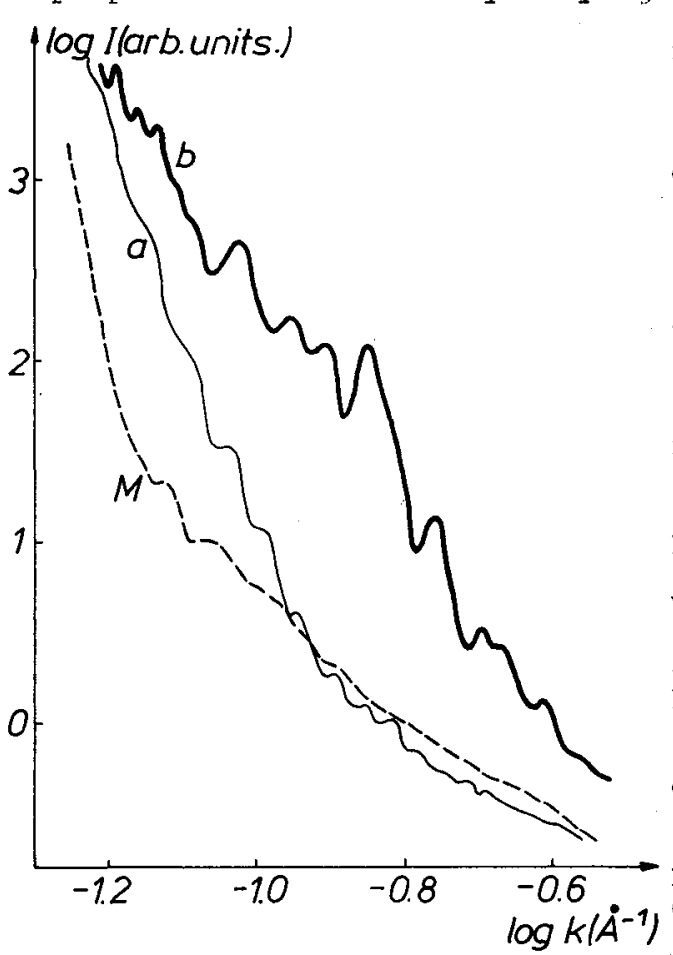
increase in amplitude with the metal concentration $\mathbf{x}$ and so does the general level of the scattered intensity in the small-angle range. For $x=0.07$ (fig.1, sample M), the oscillations are barely visible.

This effect is reminiscent of the SAXS on quasi-spherical particles and must be ascribed to zones of compositional fluctuation, where the Mo concentration is above the average value.

Information about the size and density fluctuation in these zones can be inferred from the highfrequency oscillatory part of the RSAXS intensity. This involves separating the low-frequency, monotonous intensity component $I_{V}(k)$, which is due to sample volume effects, from the total scattered intensity $I(k)$. The separation comprises two steps: substraction of and average power function in $\mathrm{k}$ and subsequent Fourier filtering of the remaining low-frequency component.

The resulting oscillatory part $k . i(k)$ of the RSAXS intensity is shown in fig. 2 for the samples with $x=0.22$ and $0.32: i(k)=(I(k) /$ $\left.I_{y}(k)\right)-1$. Multiplication by $k$ favourably reduces the weight of the low angle range, which is most affected by the finite length of the sample.

As can be seen in fig.2, the oscillatory component is rapidly damped at higher $k$, which points to a limited size range of the investigated compositional fluctuations.

A Fourier transform of $\mathrm{k.i(k)}$ yields the electron density fluctuation $\Delta_{p}=p-p_{0}$ s. the distance $R$ from an average atom in the sample (fig.3). The average electron density $p$ depends on the composition $x$.

It is to be noticed that for $x=0.22$ there is a single maximum al $R=125 \AA$. For $x=0.32$, a series of almost equally spaced peaks ap- 


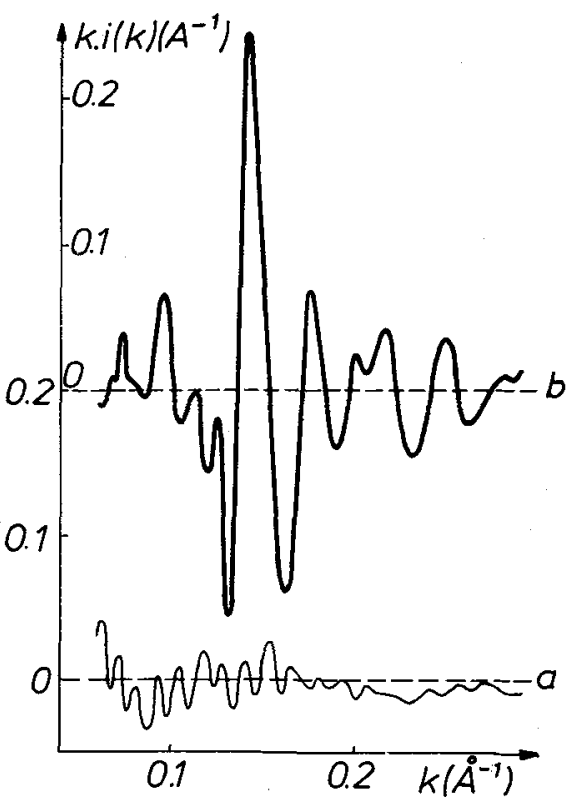

pears, indicative of a higher number of closer packed zones. The details below $80 \AA$ are residues of the low-frequency component.

The $\Delta p(R)$ dependence can be interpreted in the frame of a model, consisting in quasi-spherical Mo-rich zones, dispersed in a matrix with a Mo concentration below the average $x$. At both Mo concentrations, the Mo-Mo pair distances between zones are expected to appear as maxima in the distribution of the density fluctuations. The area of a maximum,i.e.the number of excedentary electron pairs, is expected to be $(\Delta \rho)^{2}$. On the other hand, the distribution of the Ge-Mo pair distances between the matrix and the zones should be rather featureless.

Additional suggestion about the packing of the Mo-rich zones comes from electron microscopy observations

Fig.2.Oscillatory RSAXS component for samples with $x=0.22(a)$ and $0.32(b)$.

(P.B.Barna, A.Barna, L. Toth, R. Manaila, unpublished work). They reveal for $\mathrm{x}=0.32$ a superstructure of darker, Mo-rich circular zones, superposed on to the fine-grained pattern, characteristic for homogeneous amornhous films. These zones, about $100 \AA$ in diameter, are packed rather closely in larger Mo-rich regions and are barely visible in the rest of the matrix. For $x=0.22$, this segregation of the metal is much less marked.

For a close packing of hard spheres with the diameter $D$, the prevailing pair distances are $D, 1.63 \mathrm{D}, 1.95 \mathrm{D}$, etc. [6] . Of course, the packing of the zones is not really close and they may differ by their Mo concentration, so that the above pair distances have only a hint value.By assuming for the distance of closest approach $D$ the value 96 , corresponding to the

Fig.3.Electron density fluctuation vs.k in samples with $x=0.22(a)$ and $0.32(b)$.

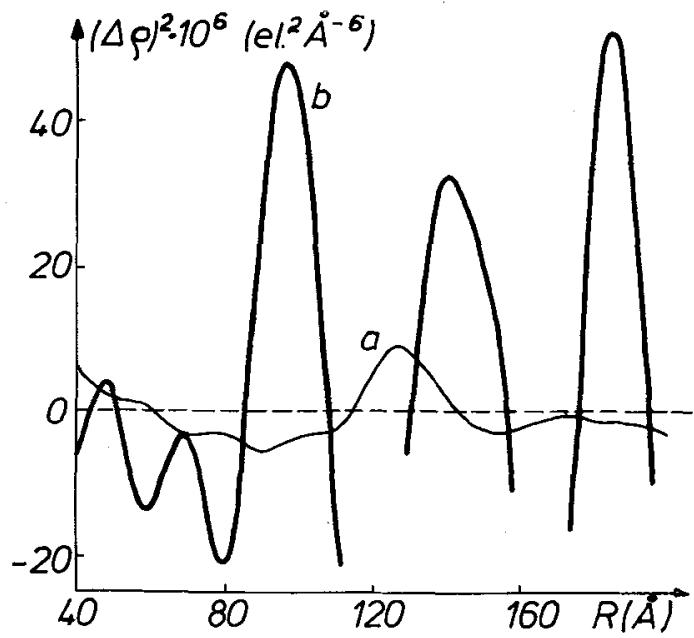

first maximum, the inter-zone distances predicted for a close packing are 157 and $187 \AA$, in rough agreement with the positions of the peaks on fig. 3 .

The data in fig. $3 \mathrm{~b}$ can also be used to estimate the magnitude of the electron density fluctuation $\Delta \rho$ for $x=0.32$. Taking into account the area $A$ of the main peak at $96 \AA$ and the probability of finding a Mo-rich zone at a given distance $R$ from another zone, $\Delta p=\sqrt{\mathrm{A}} / p$.

A rough estimate, hased on the electron microscopy observations, gives $p \simeq 0.1$, so that $\Delta p$ is found to be $\simeq 2.10^{-1} \mathrm{el} . \mathbb{R}^{-3}$. This is to be 
compared with the average electron density $\rho_{0}=8 \cdot 10^{-1}$ el. $\AA^{-3}$ contributed by the Mo atoms with the average concentration of 0.32 , pointing to rather high local variations in the $x$ value.

Thus, electron density variations, due to density or composition fluctuations in thin films, can be quantitatively assessed by RSAXS, provided the size of the fluctuations falls into a convenient range.

\section{REFERENCES}

1. PHILLIPS J.C., Phys.Rev.Lett. 42 (1979) 1151, Comments on Solid State Physics 9 (1980) 191.

2. ROTH M. , J.AppI.Cryst. 10 (1977) 172

3. BARNA A., BARNA P.B., RADNOCZI G., SUGAWARA H. and THOMAS P., Proc.Int.Topical Conf.Structure and Excitations in Amorph.Solids, Williamsburg (USA), march 1976, p.199

4. WARREN B.E., "X-ray Diffraction", Addison-Wesley, Reading, 1969, p. 142

5. BELU A., DEVENYI A., MANAILA R., MIU L., RUSU C., BARNA A., BARNA P.B., RADNOCZI G. and TOTH L., Acta Physica Hungarica (under press)

6. SADOC J.F., DIXMIER J. and GUINIER A., J.Non-Crystalline Solids 12 (1973) 46 . 